\title{
The Relationship between Active and Passive Flexibility of the Knee Flexors
}

\author{
P. Niewiadomy ${ }^{1}$, K. Szuścik-Niewiadomy ${ }^{2}$, M. Kochan ${ }^{3}$, M. T. Kuszewski ${ }^{3}$ \\ 1 Department of Balneoclimatology and Biological Regeneration, School of Health Sciences in Katowice, Medical \\ University of Silesia in Katowice, Katowice, Poland \\ 2 Department of Adapted Physical Activity and Sport, School of Health Sciences in Katowice, Medical University \\ of Silesia in Katowice, Katowice, Poland \\ 3 Institute of Physiotherapy and Health Sciences, The Jerzy Kukuczka Academy of Physical Education in Katowice, \\ Katowice, Poland
}

\author{
CORRESPONDING AUTHOR: \\ Katarzyna Szuścik-Niewiadomy \\ Department of Adapted Physical Activity \\ and Sport \\ School of Health Sciences in Katowice \\ Medical University of Silesia in Katowice \\ Medyków 8 \\ Katowice 40-752, Poland \\ E-mail: kszuscik@sum.edu.pl \\ DOI: \\ 10.32098/mltj.02.2021.21
}

LEVEL OF EVIDENCE: 3B

\begin{abstract}
SUMMARY
Background. Hamstrings flexibility measurements are of both, research and clinical relevance for evaluation of the training progression, prognosis of acute hamstrings injuries and monitoring recovery from such injuries. The active knee extension test and the passive knee extension test are widely used for hamstrings flexibility evaluation. However, they are based on different neurophysiological mechanisms.

Objective. The aim of this study was to assess the relationship between results of both tests: active knee extension test and passive knee extension test.

Methods. 314 generally healthy and physically active subjects (204 women and 110 men), aged 18-45, participated in this study. Each subject performed 3 trials of the active knee extension test and the passive knee extension test for both lower extremities and the range of motion was measured. To make the passive knee extension test more objective the force gauge was used for ensuring constant force in each repetition. The correlations between both tests were assessed using the Pearson coefficient (r). Additionally, the ICCs for intra-rater reliability were calculated.

Results. All of the outcomes revealed a significant $(\mathrm{p}<0.01)$ positive, moderately high correlation ( $\mathrm{r}$ values ranged from 0.67 to 0.73 ). Presented versions of both tests yield excellent intra-rater reliability - the ICCs (3.1) ranged from 0.98 to 0.99 . Although moderately high levels of correlation, in our opinion, both tests can be used interchangeably only for general hamstring flexibility evaluation, but in more specific assessment the suitable test should be chosen, considering passive versus active nature of the movement.

Conclusions. The PKET and the AKET are useful and reliable tools for evaluation the flexibility of hamstrings. There is a significant positive, moderately high correlation between results of both tests. In our opinion, AKET is a sufficient test for a simple clinical evaluation in everyday practice and it's recommended special for people with little experience. Additionally, in more specific clinical assessment due to the different neurophysiological mechanisms, they are based on, the choice of the tests should take into account whether the purpose of the analysis is passive versus active form of the movement.
\end{abstract}

\section{KEY WORDS}

Muscles; bamstrings; reliability; knee extension test; flexibility. 


\section{INTRODUCTION}

Flexibility is an important physical parameter often related to athletes' performance (1) and also to muscle injuries $(2,3)$. Poor flexibility, specifically affecting the hamstrings muscle group, has been linked not only to muscle strains $(4,5)$, but also to other conditions such as patellofemoral pain (6). Moreover, there is evidence that increased stiffness of hamstrings is likely to be associated with insufficient core stabilization (7). Therefore, hamstrings flexibility measurements are of both, research and clinical relevance for evaluation of the training progression, prognosis of acute hamstrings injuries and monitoring recovery from such injuries $(8,9)$.

There are many functional tests for assessing flexibility, extensibility, tightness and stiffness of hamstrings (in this study they are referred to as muscle flexibility tests), which validity and reliability has been confirmed (2, 8, 10-15). Common methods to evaluate hamstrings flexibility are active knee extension test (AKET) and passive knee extension test (PKET). In the AKET, the patient actively extends the knee until reaching maximal stretch of the hamstrings while the ipsilateral hip is kept at a fixed angle, usually $90^{\circ}$ or $120^{\circ}$ of flexion $(2,8,15)$. The PKET is performed identically except that the knee is extended passively by the rater $(8,10,15)$. The advantage of these tests is the lack of any significant movement of the hip, sacroiliac joint or lumbar spine during the test performance $(2,14,16)$.

One of the difficulties in interpretation and comparing the results of these tests lies in the fact, that passive and active flexibility are based on different neurophysiological mechanisms. The passive flexibility of muscles is influenced by the size and length of muscle fibres (series elastic components) and by the amount and arrangement of connective tissues (parallel elastic components) of the muscle belly $(17,18)$, while the result of active test is not only a function of the resistance offered by the passive properties of tissues, but it also depends on reciprocal inhibition an example of which is the ability to simultaneously contract quadriceps and relax hamstrings (13).

Another issue is to determine the end point at which the measurement of range of motion is taken. Both tests are mainly based on subjective feelings of the participant, it could be especially problematic in the PKET (8). To make the passive tests more objective, some researches $(13,19)$, instead of listening subject's indication of reaching the maximal tolerable stretch of the hamstring muscles, establish the standardized, constant force, which is applied to perform knee extension - the force values are monitored with special tools like force gauges or dynamometers.

Although the AKET and the PKET are proved to be reliable tools in assessing hamstring flexibility $(8,10,13-15)$. We have only found one study, which compare results of both tests
(15). It might be important to assess the correlation between both tests, because they are commonly used for general flexibility examination, but they refer to different kinds of flexibility - passive, which is influenced by mechanical properties of the tissue and active, which connects the mechanical properties with the nervous system control - it was assumed that, this fact might cause the divergent results of both test in single subject. The researcher has shown that there is a significant sex-related difference in the accuracy of knee joint proprioception (20), influenced by the receptors functioning, which are also responsible for stretching sensations. Due to that fact, it was hypothesised, that sex-related differences might be found in correlation coefficients too. Because of commonly confirmed human body asymmetry, it was assumed, that body site-related difference might also appear.

\section{MATERIALS AND METHODS}

\section{Study design}

The aim of this study was to assess the relationship between results of both tests: active knee extension test and passive knee extension test. Therefore, is there a strong enough correlation between them to use these tests interchangeably.

\section{Participants}

314 subjects (204 women and 110 men), aged 18-45, volunteered to participate in this study. Their mean \pm SD age, height, and weight were $24.58 \pm 4.86$ years, $171.97 \pm 8.85$ $\mathrm{cm}, 67.34 \pm 11.99 \mathrm{~kg}$, respectively. All subjects were physically active, but without engaging in competition-level sports. Participants had no history of lower limb injury that required surgery, and no history of acute lower limb injury within the last year that required a missed day of work or requirement to seek medical treatment. All participants were healthy, with no known metabolic or neuromuscular disease, and no musculoskeletal abnormalities. Other exclusion criteria were BMI $>29.9$, pregnancy and menopause. The research project obtained approval number KNW/0022/ KB46-7/15 of the Bioethics Committee of the University. All participants had given written informed consent before data collection began. The study meets the ethical standards of the journal (21).

\section{Procedures}

Two physiotherapists with many years of clinical experience were involved in the study as raters, one as the primary rater (PR) and one as the assistant (AT). Their roles did not change throughout the whole study. It was assumed that 
for unequivocally assessment of the correlation between the results of both tests, high precision will be required during the measurements, therefore experienced researchers were engaged to ensure that all tests will be characterized by adequate repeatability.

Before joining the research, each subject's medical history was evaluated. On the day of measurements, the demonstration of testing procedures took place. All data were collected in a single testing session. Before measurements, the participants performed a short 10-minute warm-up at average intensity using a stationary bike ( $5 \mathrm{~min}$ ) and elliptical bike $(5 \mathrm{~min})$ with a low load to standardize the amount of activity. Then, the PKET and the AKET were performed consecutively. The passive test was performed prior to the active one assuming that the AKET would cause reciprocal inhibition in the hamstrings (22), which was noticed and analysed at the stage of the pilot study. The digital inclinometer (Saunders Group Inc., Chaska, USA) was used to record the knee motion degree during both tests (figure 1). The larger the angle indicated by inclinometer, the greater flexibility. Tested accuracy of the device proved to be $\pm 1^{\circ}$. Additionally, in the PKET, we used the Advanced Force Gauge (Mecmesin, Slinfold, West Sussex, UK) to determine the end point, at which the measurement was taken - it helped to make the procedures more objective.

Each measurement was taken 3 times for right and left side in random order to test its reliability. Subsequent statistical analyses were based on the mean value of these three repetitions. Prior to the main study, the researchers carried out a pilot study, which included 5 randomly selected individuals, to validate measurement procedures and to eliminate potential errors.

\section{Passive knee extension test}

The PKET (figure 2) was performed according to the methodology described by Gnat et al. (10) and Kuszewski et al. (19). The whole test was carried out with the subject's maximum relaxation. Participant was positioned supine with the hip of the tested leg in $90^{\circ}$ of flexion, stabilized with the

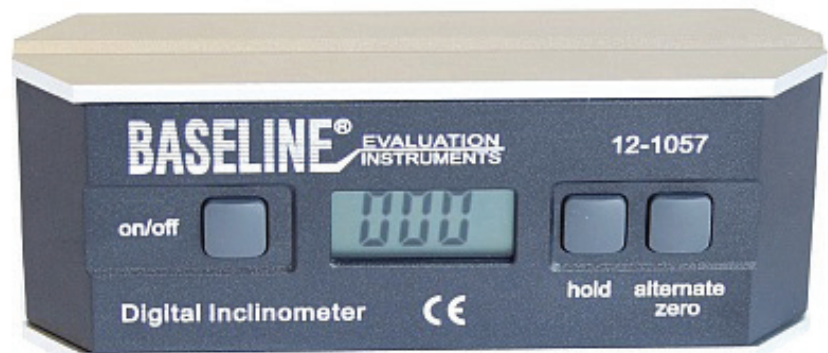

Figure 1. The digital inclinometer Saunders Group.
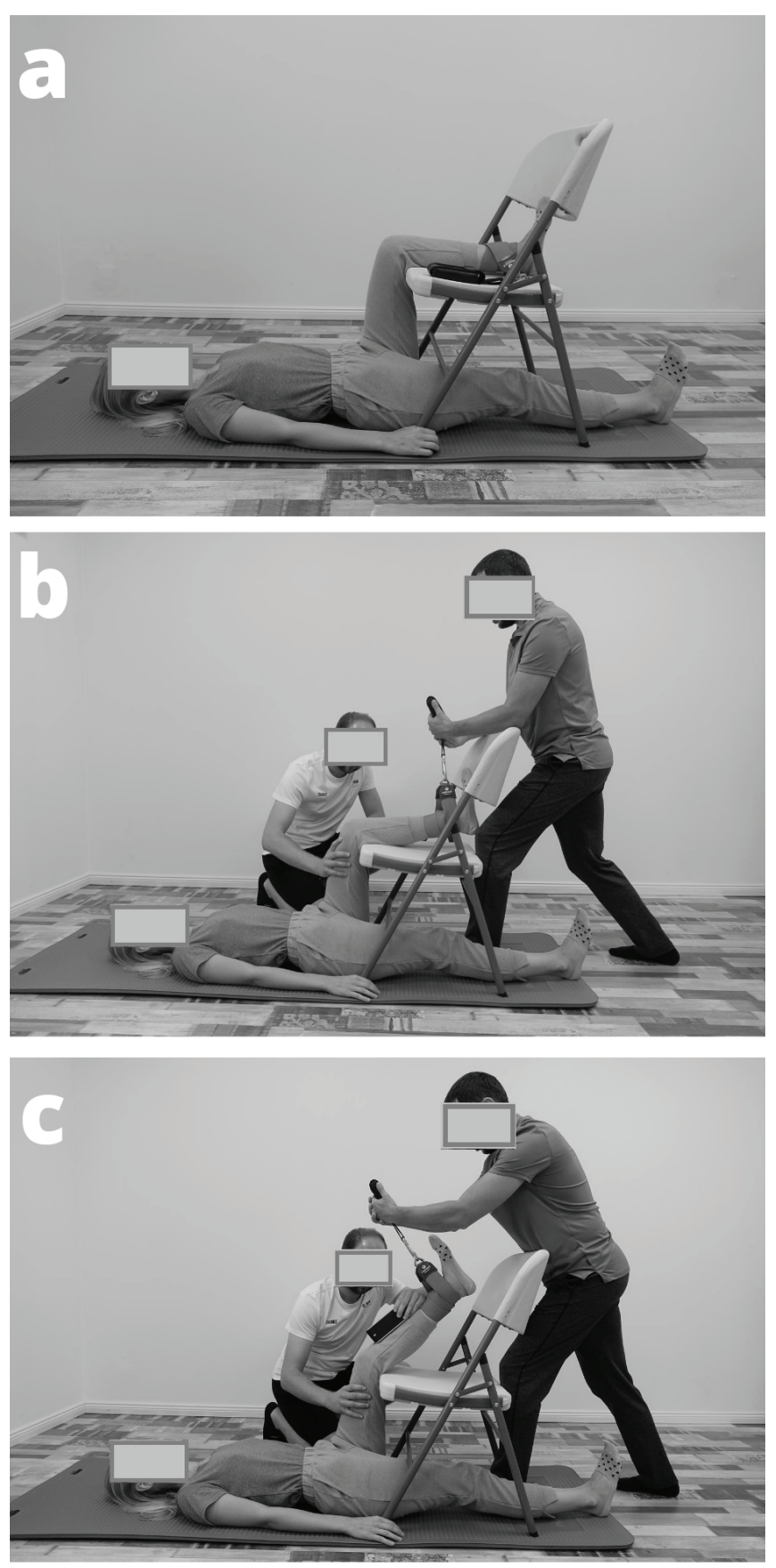

Figure 2. The passive knee extension test.

stool that was placed under the posterior aspect of the tested thigh and held with the help of the subject's hands (figure 2 a). Before testing, the force gauge was attached to the tested extremity, exactly on the line joining the 2 malleoli. From this position, the PR firstly placed the extremity in a $90^{\circ}$ of knee flexion so that the shank did not lean on the stool. Then, 
the force gauge was reset to eliminate the specific weight of the shank from the measurement (figure $\mathbf{2}$ b). Next, the PR passively extended the subject's knee (maintaining the position of the device perpendicular to the long axis of the shin) until the force gauge indicated $2.5 \mathrm{~kg}$ (figure $2 \mathrm{c}$ ). This value is very similar to the parameters presented by Kuszewski et al. (19) and had been checked during our pilot study. It does not trigger nociceptive effects and therefore, the stretch reflex does not occur; it also does not require a lot of strength from the researcher and allows for proper distinguishing levels of passive stiffness, especially referring to very flexible subjects it helps to avoid situations in which the researcher reaches the full range of passive motion before the dynamometer indicates the assumed force value. The AT's task during the passive movement was to stabilize the thigh of tested and to visually control the maintaining position of contralateral extremity without knee flexion.

At the end point, when the force gauge indicated assumed value of applied force, the angle between anterior surface of shin and horizontal plane was registered by the AT with the digital inclinometer positioned at the anterior tibial border, halfway between apex of the patella and the line between the 2 malleoli. Both, the subject and the PR were blinded to the readings.

\section{Active knee extension test}

The initial position for the AKET (figure 3) was the same as for the PKET (figure 3 a). The subject was instructed to perform active knee extension by himself/herself, until reaching the maximal tolerable stretch of the hamstrings and maintain the position (this time the force gauge was not used). During the whole movement the contralateral extremity was stabilized by means of firm manual pressure applied by the $\mathrm{PR}$ in the middle-anterior aspect of the thigh (figure $\mathbf{3} \mathbf{b}$ ). At the end point the AT placed the inclinometer at the anterior surface of the shin and registered the angle between horizontal plane, once again both, the subject and the PR were blinded (figure $3 \mathbf{c}$ ).

\section{Statistical analysis}

The correlations between both tests were assessed using the Pearson coefficient $(r)$ with regard to all subjects, as well as women and men separately (concerning right and left extremity). The independent t-test was used to compare results obtained by females to males and in the right extremity to the left. The level of significance was set at $\mathrm{p} \leq 0.05$. Additionally, the ICCs (3.1) for intra-rater reliability of both tests (for each extremity) were calculated.

All statistical analyses were performed using the Statistica 13 software.
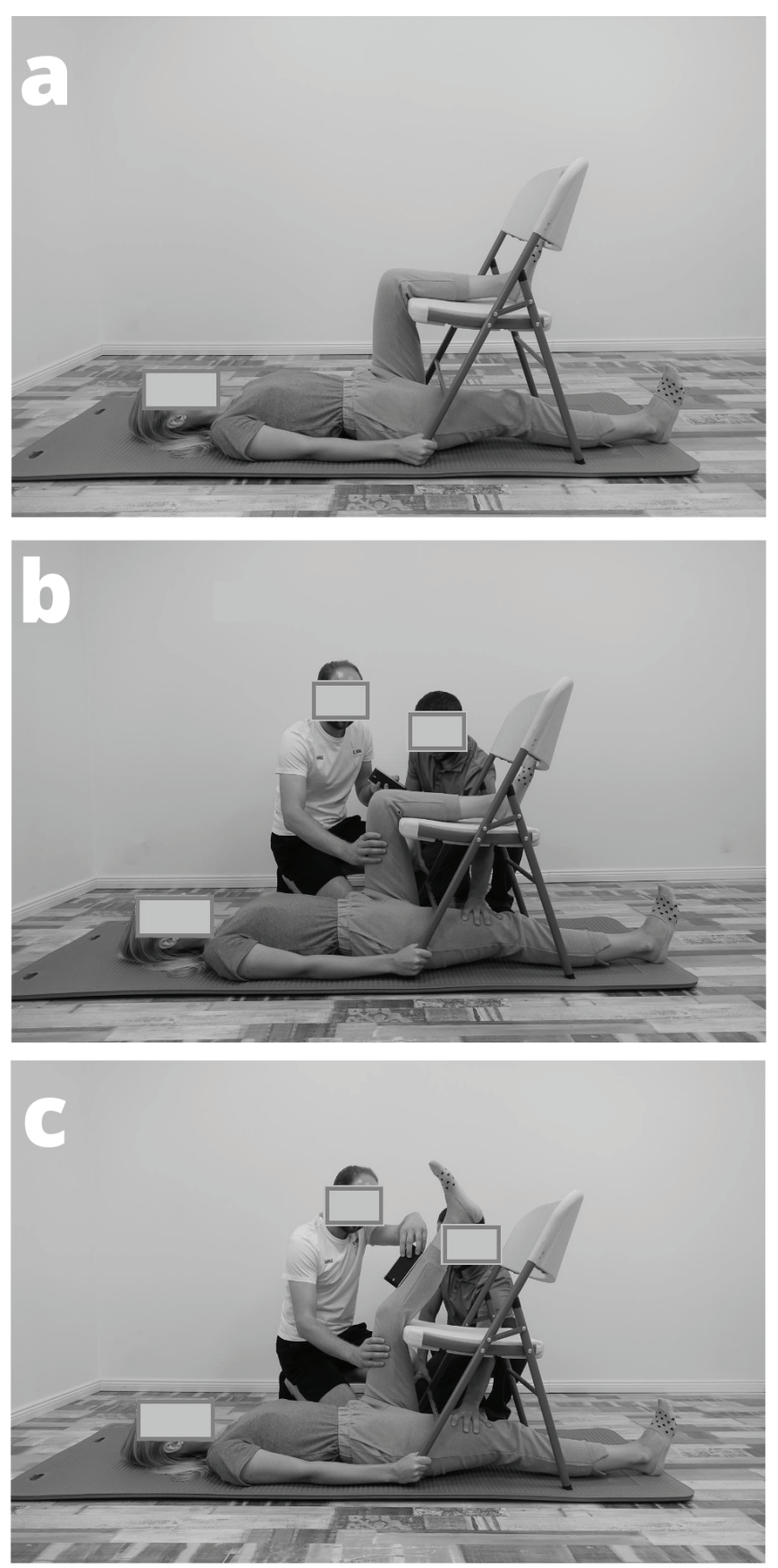

Figure 3. The active knee extension test.

\section{RESULTS}

The angular results of the PKET and the AKET are presented in table I. The outcomes obtained by females differ significantly in comparison to males $(\mathrm{p}<0.01)$. We found no significant differences in the mean values of both tests between the right and the left side $(\mathrm{p}>0.05)$. 
The Pearson coefficients are presented in table II. All of the outcomes revealed a significant $(\mathrm{p}<0.01)$ positive, moderately high correlation.

The intra-rater ICCs (3.1) were $=0.99$ in the AKET for each extremity and in the PKET for right lower extremity; and = 0.98 in the PKET for left lower extremity.

\section{DISCUSSION}

The angular values of the PKET obtained in this study are similar to those presented by Kuszewski et al. (19) in healthy subjects - mean value was $144.7^{\circ} \pm 17.8^{\circ}$ (without sex differentiation), including $90^{\circ}$ of initial flexion. Based on our formula it would be $54.7^{\circ}$, which is a little bit higher result than ours. It could be the effect of greater force applied during the test ( $30 \mathrm{~N}$ to $2.5 \mathrm{~kg}$ in our study). The mean results of the AKET presented by Yildirım et al. (22), according to our formula of measuring, would be $84.9^{\circ} \pm 8.2^{\circ}$ for the right leg and $83.9^{\circ} \pm 8.5^{\circ}$ for the left. These values are also slightly higher than our outcomes, but the research was conducted on younger subjects. Moreover, in both cited studies the research groups were smaller than in ours.
However, the main purpose of presented study was to assess the relationship between the AKET and the PKET in healthy, generally active adults. The results we have obtained, revealed a significant positive, moderately high correlation between both tests, regarding men, women and subjects of both sexes taken together (concerning right, as well as left extremity). Our outcomes are consistent with research of Gajdosik et al. (15) $(\mathrm{r}=0.64)$ - the only publication we have found, which had previously compared passive and active knee extension tests. However, the research group in that study included only 30 male subjects with right extremity tested. In our study we have rated many more participants of both sexes and the tests were performed for right and left side to catch the asymmetry, if any appear (afterwards, our results did not revealed any significant differences in the mean values of both tests between the right and the left extremity). Despite the fact that women were significantly more flexible in both tests than men, the correlation coefficients between the results of PKET and AKET were very similar. In the literature there are also studies, which show correlation between the AKET and another passive test for hamstring flexibility evaluation (straight leg rise (SLR)), but

Table I. The angular values $\left(^{\circ}\right)$ of the passive and active knee extension tests.

\begin{tabular}{|c|c|c|c|c|c|c|}
\hline & & $\begin{array}{l}\text { Female } \\
(n=204)\end{array}$ & $\begin{array}{l}\text { Male } \\
(n=110)\end{array}$ & $\begin{array}{l}\text { Total } \\
(n=314)\end{array}$ & $\begin{array}{l}\text { Sex-related } \\
\text { difference p-value }\end{array}$ & $\begin{array}{l}\text { Body site-related } \\
\text { difference p-value }\end{array}$ \\
\hline \multirow[t]{3}{*}{ PKET right } & Mean \pm SD & $51.6 \pm 11.6$ & $45.7 \pm 12.5$ & $49.5 \pm 12.2$ & 0.000 & \multirow{5}{*}{0.304} \\
\hline & Lower quartile & 45.2 & 38.3 & 41.7 & & \\
\hline & Upper quartile & 58.7 & 53.0 & 56.3 & & \\
\hline \multirow{2}{*}{ PKET left } & Lower quartile & 43.0 & 37.0 & 40.8 & \multirow{2}{*}{0.000} & \\
\hline & Upper quartile & 57.3 & 53.3 & 55.7 & & \\
\hline \multirow[t]{2}{*}{ AKET right } & Mean \pm SD & $72.9 \pm 11.0$ & $68.5 \pm 12.3$ & $71.3 \pm 11.6$ & \multirow[t]{2}{*}{0.001} & \multirow{5}{*}{0.268} \\
\hline & Min-Max & $45.0-92.0$ & 45.0-90.0 & 45.0-92.0 & & \\
\hline \multirow{3}{*}{ AKET left } & Min-Max & $44.7-92.0$ & $39.5-89.3$ & $39.5-92.0$ & \multirow{3}{*}{0.001} & \\
\hline & Lower quartile & 64.2 & 56.3 & 60.5 & & \\
\hline & Upper quartile & 81.3 & 77.7 & 80.0 & & \\
\hline
\end{tabular}

Table II. The Pearson coefficients $(r)$ between the AKET and PKET.

\begin{tabular}{llll} 
& $\mathbf{n}$ & Right leg & Left leg \\
\hline Total & 314 & 0.73 & 0.69 \\
\hline Women & 204 & 0.72 & 0.67 \\
\hline Men & 110 & 0.73 & 0.69 \\
\hline
\end{tabular}


the outcomes are not patchy. Neto et al. (2) obtained $r=0.71$ and $\mathrm{r}=0.67$ (depending on the side), while Gajdosik et al. (15) revealed $r=0.43$ and $r=0.37$ (depending on the modification of the SLR). Considering this, although our results show moderately high levels of correlation, we suggest being very precise in choosing the test variant, because they are based on different neurophysiological mechanisms, which could cause the difference in the outcome of both tests. The resistance to passive lengthening is influenced by the readily adaptable amount of muscle tissue, including the contractile proteins and the non-contractile proteins of the sarcomere cytoskeletons (17); while the active flexibility is associated not only with passive tissue properties, but also with the excitability of the motoneuron pool and the level of muscle activation (23).

In addition to the main purpose of the study, we have also evaluated the intra-rater reliability of the PKET and the AKET. Presented versions of both tests yield excellent reliability. Other studies showed high values of test-retest ICCs too, but not as perfect as ours $(2,15)$. The researchers also found high inter-tester reliability regarding both tests $(8$, $10,12,13)$. What is more, the tests turned out to be very reliable in acute hamstring injuries, without including any sophisticated tools, except for inclinometers (8). Performing the tests, some issues could appear with the indication of "a strong but tolerable stretch" feeling. According to the references, it seems that patients could better indicate the point of maximal tolerable stretch while actively extending the knee, compared with passive extension of the knee by the rater (8). Although the nature of this sensation is entirely subjective, we attempted to make this more "objective" during the PKET by using the force gauge in consecutive repetitions. This probably was one of the reasons of obtaining such highly values of ICC. Moreover, in our study all the measurements were performed by the same two physiotherapists, so they gained a lot of experience during testing so many subjects, which also may be reflected in ICC values.

From a clinical point of view, the high intra-rater reliability values obtained in this study lead us to believe that the PKET and the AKET can be useful in physiotherapist's/ trainer's daily work to measure length of the hamstrings. Both tests are easily to perform and, as researches show, even raters with not much experience in clinical practice can do

\section{REFERENCES}

1. Sexton P, Chambers J. The importance of flexibility for functional range of motion. Athl Ther Today 2006;3:13-17.

2. Neto T, Jacobsohn L, Carita AI, Oliveira R. Reliability of the active-knee-extension and straight-leg-raise tests it well $(10,12)$. The moderately high levels of correlations, that we presented in the study, in our opinion, allow to use both tests interchangeably, but only for general hamstring flexibility evaluation. For the precise muscle tissue properties assessment, especially in research work, the suitable test should be chosen, considering passive versus active nature of the movement and the specific purpose of the assessment. The presented study has some limitations. We assessed only healthy, quite young, asymptomatic subjects, so we do not know how other clinical populations might respond. Due to the main purpose of the study was to assess correlations between the PKET and the AKET, we wanted to obtain very precise results of measurement, which is why we only involved one PR - in that case we were not able to evaluate the inter-tester reliability, but it is well documented in the literature. Another issue is that although both tests are commonly used for hamstring flexibility evaluation, changes to neural structures, for example the sciatic nerve, are also likely to occur during the tests $(12,24)$. The neural mechano-sensitivity may play a significant role in the end point feeling of "a strong but tolerable stretch" (24). We think that future studies should compare the functional tests for hamstring flexibility assessment with the results of measurements, like myotonometry (25), which would not involve neural structures during muscle tone evaluation.

\section{CONCLUSIONS}

The PKET and the AKET are useful and reliable tools for evaluation the flexibility of hamstrings. There is a significant positive, moderately high correlation between results of both tests.

In our opinion, AKET is a sufficient test for a simple clinical evaluation in everyday practice and it's recommended special for people with little experience. Additionally, in more specific clinical assessment due to the different neurophysiological mechanisms, they are based on, the choice of the tests should take into account whether the purpose of the analysis is passive versus active form of the movement.

\section{CONFLICT OF INTERESTS}

The authors declare that they have no conflict of interests.

in subjects with flexibility deficits. J Sport Rehabil 2015 3;24:2014-0220.

3. Witvrouw E, Danneels L, Asselman P, et al. Muscle flexibility as a risk factor for developing muscle injuries in male profes- 
sional soccer players. A prospective study. Am J Sports Med 2003;31:41-46.

4. Bradley P, Portas M. The relationship between preseason range of motion and muscle strain injury in elite soccer players. J Strength Cond Res 2007;21:1155-9.

5. Heiderscheit BC, Sherry M, Silder A, Shumanov E, Thelen D. Hamstring strain injuries: recommendations for diagnosis, rehabilitation, and injury prevention. J Orthop Sports Phys Ther 2010;40:67-81.

6. Witvrouw E, Lysens R, Bellemans J, Cambier D, Vanderstraeten G. Intrinsic risk factors for the development of anterior knee pain in an athletic population: a two-year prospective study. Am J Sports Med 2000;28:480-9.

7. Kuszewski MT, Gnat R, Saulicz E. Stability training of the lumbo-pelvo-hip complex influence stiffness of the hamstrings: a preliminary study. Scand J Med Sci Sports 2009;19:260-6.

8. Reurink G, Goudswaard GJ, Oomen HG, Moen MH, Tol JL, Verhaar JA, Weir A. Reliability of the active and passive knee extension test in acute hamstring injuries. Am J Sports Med 2013;41:1757-61.

9. Kerkhoffs GM, van Es N, Wieldraaijer T, Sierevelt IN, Ekstrand $\mathrm{J}$, van Dijk CN. Diagnosis and prognosis of acute hamstring injuries in athletes. Knee Surg Sports Traumatol Arthrosc 2013;21:500-9.

10. Gnat R, Kuszewski M, Koczar R, Dziewońska A. Reliability of the passive knee flexion and extension tests in healthy subjects. J Manipulative Physiol Ther 2010;33:659-65.

11. Ayala F, Sainz de Baranda P, De Ste Croix M, Santonja F. Absolute reliability of five clinical tests for assessing hamstring flexibility in professional futsal players. J Sci Med Sport 2012;15:142-7.

12. Norris CM, Matthews M. Inter-rater reliability of a self-monitored active knee extension test. J Bodyw Mov Ther 2019;9:256-9.

13. Fredriksen H, Dagfinrud H, Jacobsen V, Maehlum S. Passive knee extension test to measure hamstring muscle tightness. Scand J Med Sci Sports 1997;7:279-82.

14. Gajdosik R, Lusin G. Hamstring muscle tightness. Reliability of an active-knee-extension test. Phys Ther 1983;63:1085-8.
15. Gajdosik RL, Rieck MA, Sullivan DK, Wightman SE. Comparison of four clinical tests for assessing hamstring muscle length. J Orthop Sports Phys Ther 1993;18:614-8.

16. Rakos DM, Shaw KA, Fedor RL, Lamanna M, Yocum CC, Lawrence KJ. Interrater reliability of the active-knee-extension test for hamstring length in school-aged children. Pediatr Phys Ther 2001;13:37-41.

17. Gajdosik RL. Passive extensibility of skeletal muscle: review of the literature with clinical implications. Clin Biomech (Bristol, Avon) 2001;16:87-101.

18. Marshall PW, Cashman A, Cheema BS. A randomized controlled trial for the effect of passive stretching on measures of hamstring extensibility, passive stiffness, strength, and stretch tolerance. J Sci Med Sport 2011;14:535-40.

19. Kuszewski MT, Gnat R, Szlachta G, Kaczyńska M, Knapik A. Passive stiffness of the hamstrings and the rectus femoris in persons after an ACL reconstruction. Phys Sportsmed 2019;47:91-5.

20. Karkousha RN. Sex differences of knee joint repositioning accuracy in healthy adolescents. Bull Fac Phys Ther 2016;21:56-60.

21. Padulo J, Oliva F, Frizziero A, Maffulli N. Muscle, Ligaments and Tendons Journal - Basic principles and recommendations in clinical and field Science Research: 2018 update. Muscles Ligaments Tendons J 2018;8(3):305-7.

22. Yıldırım MŞ, Tuna F, Demirbağ Kabayel D, Süt N. The cut-off values for the diagnosis of hamstring shortness and related factors. Balkan Med J 2018;35:388-93.

23. Kuszewski M, Gnat R, Sobota G, Myśliwiec A. Influence of passive stiffness of hamstrings on postural stability. J Hum Kinet 2015;45:49-57.

24. Kuilart KE, Woollam M, Barling E, Lucas N. The active knee extension test and Slump test in subjects with perceived hamstring tightness. International J Osteopath Med 2005;8:89-97.

25. Pruyn EC, Watsford ML, Murphy AJ. Validity and reliability of three methods of stiffness assessment. J Sport Health Sci 2016;5:476-83. 